\title{
Can Pentraxin-3 be a Candidate Marker in the Follow-Up of the Patients With Behçet's Disease?
}

\author{
Banu ALPASLAN MESCİ, ${ }^{1}$ Banu İşBİLEN BAŞOK, ${ }^{2}$ Hatice GÜL SAĞUN, ${ }^{1}$ Gökhan GÖNENLİ, ${ }^{1}$ \\ Mukaddes KAVALA, ${ }^{3}$ Esen KASAPOĞLU GÜNAL, ${ }^{4}$ Esra EKİZ, ${ }^{5}$ Ferruh İŞMAN, ${ }^{2}$ Aytekin OĞUZ ${ }^{1}$ \\ ${ }^{1}$ Department of Internal Medicine, Medeniyet University Göztepe Training and Research Hospital, İstanbul, Turkey \\ ${ }^{2}$ Department of Biochemistry, Medeniyet University Göztepe Training and Research Hospital, İstanbul, Turkey \\ ${ }^{3}$ Department of Dermatology, Medeniyet University Göztepe Training and Research Hospital, İstanbul, Turkey \\ ${ }^{4}$ Department of Rheumatology, Medeniyet University Göztepe Training and Research Hospital, Istanbul, Turkey \\ ${ }^{5}$ Department of Internal Medicine, Esenler Women's \& Children Hospital, İstanbul, Turkey
}

\begin{abstract}
Objectives: This study aims to assess the level of pentraxin-3 (PTX-3) as an inflammatory marker and compare it with C-reactive protein (CRP) levels in patients with Behçet's disease (BD).

Patients and methods: Forty-two patients with BD (15 males, 27 females; mean age $39.7 \pm 8.6$ years; range 20 to 64 years) and 42 age- and sex-matched healthy controls ( 14 males, 28 females; mean age $40.8 \pm 8.2$ year; range 25 to 60 years) were included in the study. Serum CRP and plasma PTX-3 levels were measured. Subgroup analyses were performed according to clinical manifestations of patients with BD.

Results: Both PTX-3 and CRP levels were significantly higher in patients with BD than controls $(1.33 \pm 0.29$ vs $0.85 \pm 0.12, p<0.05$ for PTX-3 and $0.71 \pm 0.13$ vs $0.27 \pm 0.03, p<0.001$ for CRP, respectively). Area under the curve was $0.633 \pm 0.062$ vs $0.729 \pm 0.05$, respectively. Mean PTX-3 and CRP levels were 1.1 vs $1.5, p=0.5 ; 0.5$ vs $0.9, p=0.5$; respectively, in patients with mucocutaneous involvement alone and with other involvements, whereas they were 0.9 vs $1.6, p=0.1 ; 0.5$ vs $0.8, p=0.3$; respectively, in patients with and without peripheral arthritis, and were 1.7 vs $0.9, p=0.06 ; 1.0$ vs $0.5, p=0.07$; respectively, in patients with and without uveitis.

Conclusion: Although PTX-3 levels were higher in patients with BD than healthy controls, sensitivity and specificity of PTX-3 was not different than CRP in patients with BD.

Keywords: Behçet's disease; cytokine; inflammation.
\end{abstract}

Behçet's disease (BD) is a chronic, relapsing multisystemic disease characterized with nonspecific vasculitis that affects various sizes of vessels. The highest prevalence was reported in the Eastern Mediterranean and in Asia. ${ }^{1,2}$ Inherited and adaptive immunity accompanied with bacterial and viral infections, activations of neutrophils, natural killers, and cytotoxic T cells were found to be responsible in the etiology. ${ }^{3-5}$ BD's association with human leukocyte antigen-B51 (HLA-B51) gene is well known, however there is no certain laboratory parameter for the diagnosis or follow-up of BD. Pentraxins (PTXs) are acute phase proteins that affect humoral arm of congenital immunity. ${ }^{6}$ They are divided into two groups as short and long PTXs. ${ }^{7,8} \mathrm{C}$-reactive protein (CRP) is the prototype of the short PTX family mainly produced in the liver in response to inflammatory signals and PTX-3 is the prototype of the long PTX family. ${ }^{9,10}$ While CRP is produced by hepatocytes, PTX-3 is produced by different cell types and functions locally. Different from classic PTXs, PTX-3 is secreted as a response to interleukin- 1 beta and tumor necrosis factor alpha. PTX-3 plays a complex role in vivo, recognizing a diverse range of pathogens modulating complement activity by

Received: July 04, 2016 Accepted: August 01, 2016 Published online: December 15, 2016

Correspondence: Esra Ekiz, MD. Esenler Kadın Doğum ve Çocuk Hastalıkları Hastanesi, Iç Hastalıkları Kliniği, 34230 Esenler, İstanbul, Turkey.

Tel: +90 212 - 4403900 e-mail: dr.esra@gmail.com

@2017 Turkish League Against Rheumatism. All rights reserved. 
binding $\mathrm{C} 1 \mathrm{q}$ and facilitating pathogen recognition by macrophages and dendritic cells. Because of this extrahepatic synthesis in contrast to CRP, PTX-3 levels are believed to be a more reliable indicator of disease activity produced at sites of inflammation. ${ }^{11}$ Increased levels of PTX-3 have been observed in some autoimmune disorders. ${ }^{11,12}$ In small vessel vasculitis, PTX-3 levels correlate with clinical activity of the disease and represent a candidate marker for monitoring the disease. ${ }^{11}$ Nevertheless, there is only one recent report investigating PTX-3 association in patients with BD and BD's activity. Therefore, in this study, we aimed to assess the level of PTX-3 as an inflammatory marker and compare it with CRP levels in patients with BD.

\section{PATIENTS AND METHODS}

Forty-two BD patients (15 males, 27 females; mean age $39.7 \pm 8.6$ years; range 20 to 64 years), who attended Rheumatology Clinic at the Department of Internal Medicine, Medeniyet University Göztepe Training and Research Hospital between January 2011 and June 2011 and were diagnosed according to the International Study Group of BD, ${ }^{13}$ and 42 healthy controls (14 males, 28 females; mean age $40.8 \pm 8.2$ year; range 25 to 60 years) were included. Exclusion criteria were disorders and habits that may affect inflammatory state (i.e. diabetes mellitus, dyslipidemia, malignancy, other rheumatologic or inflammatory disease, alcohol consumption, smoking, drug use). The present study was approved by the Ethical Board (01.04.2011 dated, decision no: 11/C) and written informed consent was obtained from all patients. The study was conducted in accordance with the principles of the Declaration of Helsinki. Morning blood samples were taken after an overnight fasting. Blood samples were centrifuged at $1,500 \mathrm{~g}$ for 10 minutes at room temperature within two hours after collection. Serum CRP was measured by nephelometric method (Immage ${ }^{\circledR}$ Immunochemistry System, Beckman Coulter, USA)

Table 1. Laboratory findings of patients with Behçet's disease

\begin{tabular}{lcc}
\hline & Values & Normal range \\
\hline Hemoglobin (g/dL) & 10.7 & $11.7-15.5$ \\
Hematocrit (\%) & 32.4 & $37-44$ \\
Leukocyte count (mcrL) & 9.24 & $3.800-11.000$ \\
Platelet (mcrL) & 291.000 & $150.000-350.000$ \\
Erythrocyte sedimentation rate (mm/h) & 9 & $0-20$ \\
C-reactive protein (mg/L) & 0.72 & $0-6$ \\
Urea (g/dL) & 119 & $13-43$ \\
Creatinine (mg/dL) & 1.48 & $0.7-1.3$ \\
Rheumatoid factor (IU/mL) & 14.0 & $0-18$ \\
Anti-CCP (unit/mL) & 0.6 & $0-2.5$ \\
ANA & $1:>1000$ granular pattern & Negative \\
Anti-SSA & ++ Positive & Negative \\
Anti-SSB & +++ Positive & Negative \\
Ro-52 (52 Kda) & +++ Positive & Negative \\
ANCA & Negative & Negative \\
Anticardiolipin IgM/IgG & Negative & Negative \\
Venereal disease research-RPR test & Negative & Negative \\
Complement component 4 (C4) (mg/dL) & 22.9 & $15-50$ \\
Double-stranded DNA (dsDNA) antibody & Negative & Negative \\
Direct Coombs test (IgG) & ++++ Positive & Negative \\
\hline Anti-CCP: Anti-cyclic citrullinated peptide; ANA: Antinuclear antibody; Anti-SSA: Anti Sjogren syndrome A; Anti-SSB: Anti \\
Sjogren syndrome A; ANCA: Anti-neutrophil cytoplasmic antibody; RPR: Rapid plasma regain; dsDNA: Double stranded \\
Deoxyribonucleic acid; IgG: Immunoglobulin G.
\end{tabular}


Table 2. Comparison of inflammatory markers between two study groups

\begin{tabular}{|c|c|c|c|c|c|c|c|}
\hline & \multicolumn{3}{|c|}{ Healthy controls $(n=42)$} & \multicolumn{3}{|c|}{ Patients with BD (42) } & \multirow[b]{2}{*}{$p$} \\
\hline & $\mathrm{n}$ & Mean \pm SD & Mean \pm SEM & $\mathrm{n}$ & Mean \pm SD & Mean \pm SEM & \\
\hline \multicolumn{8}{|l|}{ Gender } \\
\hline Males & 14 & & & 15 & & & \\
\hline Females & 28 & & & 27 & & & \\
\hline C-reactive protein (mg/dL) & & & $0.27 \pm 0.03$ & & & $0.71 \pm 0.13$ & $<0.001$ \\
\hline Erythrocyte sedimentation rate $(\mathrm{mm} / \mathrm{hr})$ & & $20.1 \pm 11.0$ & & & $24.3 \pm 16.5$ & & $>0.05$ \\
\hline Pentraxin-3 (ng/mL) & & & $0.85 \pm 0.12$ & & & $1.33 \pm 0.29$ & $<0.05$ \\
\hline
\end{tabular}

as a part of daily clinical practice. Plasma (ethylenediaminetetraacetic acid-anticoagulated) samples were stored at $-200{ }^{\circ} \mathrm{C}$ until analysis. Plasma PTX-3 concentration was measured by using the commercially available enzyme-linked immunosorbent assay kit (Quantikine Human Pentraxin 3/TSG-14 Immunoassay, R\&D Systems, Minneapolis, USA). The analytic sensitivity of the test was $0.025 \mathrm{ng} / \mathrm{mL}$, and the intra-assay variation coefficient $(\mathrm{CV} \%)$ for the three separate concentrations were 3.8 (mean value: $2.61 \pm 0.01$, $\mathrm{n}=20$ ), 3.7 (mean value: $7.72 \pm 0.28, \mathrm{n}=20$ ), and 4.4 (mean value: $14.1 \pm 0.62, \mathrm{n}=20$ )

\section{Statistical analysis}

The data were expressed as mean \pm standard deviation $(\mathrm{SD})$ or mean \pm standard error of the mean (SEM). Statistical analysis was performed using SPSS version 16.0 for Windows (SPSS Inc., Chicago, IL, USA). Comparison between the groups were made with unpaired t-test and MannWhitney $\mathrm{U}$ test, as appropriate. Correlations were performed by the Spearman rank test. The clinical performance of CRP and PTX-3 were assessed using receiver operating characteristics curves and calculated likelihood ratios for two cut-points with either high sensitivity or high specificity. A $p$ value of $<0.05$ was considered to be statistically significant.

\section{RESULTS}

All the patients with $\mathrm{BD}$ were under treatment and their clinical data can be seen in Table 1. Both CRP and PTX-3 levels were significantly higher among patients with $\mathrm{BD}$ than healthy controls $(0.71 \pm 0.13$ vs $0.27 \pm 0.03, p<0.001$ for CRP and $1.33 \pm 0.29$ vs $0.85 \pm 0.12, \quad \mathrm{p}<0.05$ for PTX-3; respectively) (Table 2). Nevertheless, increases in PTX-3 and CRP levels were similar (area under the curve: $0.633 \pm 0.062$ vs $0.729 \pm 0.05$; respectively) (Figure 1). Subgroup analyses were performed according to clinical features of BD. Mean PTX-3 and CRP levels were 1.1 vs $1.5, p=0.5$; 0.5 vs $0.9, \mathrm{p}=0.5$; respectively, in patients with mucocutaneous involvement alone and with other involvements; whereas they were 0.9 vs $1.6, p=0.1$; 0.5 vs $0.8, p=0.3$; respectively, in patients with and without peripheral arthritis; and 1.7 vs 0.9 , $\mathrm{p}=0.06 ; 1.0$ vs $0.5, \mathrm{p}=0.07$; respectively, in patients with and without uveitis (Table 3).

\section{DISCUSSION}

In the present study, we determined that PTXs, both CRP and PTX-3, which are inflammation

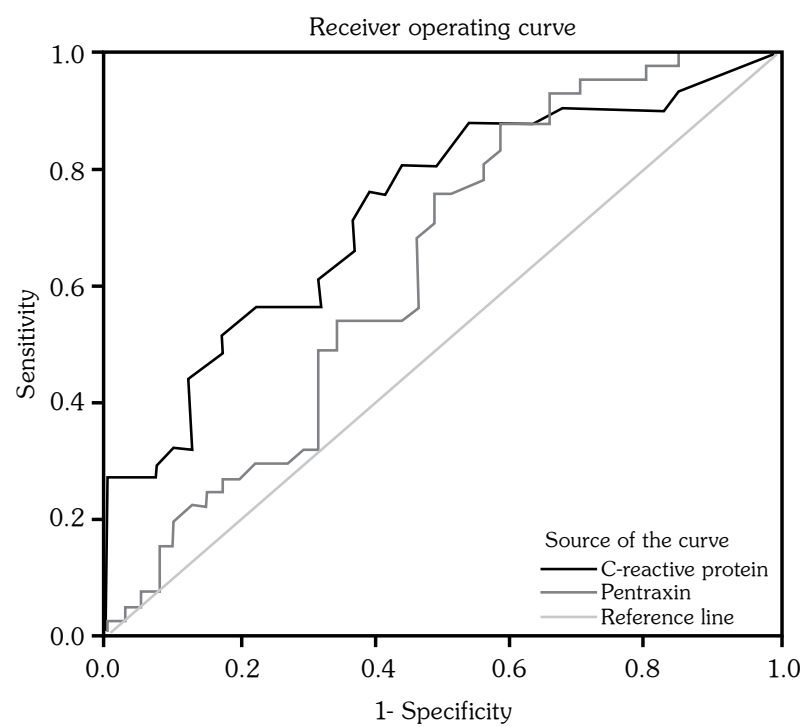

Figure 1. Sensitivities of C-reactive protein and Pentraxin-3. 


\begin{tabular}{|c|c|c|c|c|c|c|}
\hline & Pentraxin-3 & $p$ & CRP & $p$ & ESR & $p$ \\
\hline $\begin{array}{l}\text { With only mucocutaneus }(n=18) \text { vs } \\
\text { with other involvement }(n=26)\end{array}$ & 1 vs 1.5 & 0.5 & 0.5 vs 0.9 & 0.59 & 20 vs 27 & 0.5 \\
\hline $\begin{array}{l}\text { With uveitis ( } n=18) \text { vs } \\
\text { without uveitis }(n=21)\end{array}$ & 1.7 vs 0.9 & 0.06 & 1.0 vs 0.5 & 0.07 & 29 vs 19 & 0.07 \\
\hline $\begin{array}{l}\text { With peripheral arthritis }(n=15) \text { vs } \\
\text { without peripheral arthritis }(n=22)\end{array}$ & 0.9 vs 1.6 & 0.1 & 0.5 vs 0.8 & 0.3 & 24 vs 25 & 0.3 \\
\hline
\end{tabular}

markers, were significantly higher in patients with BD. Nevertheless, specificity and sensitivity of PTX-3, which is a novel long PTX, were similar to those of CRP. In previous studies, it was hypothesized that PTX-3, unlike CRP, may be a rapid marker for primary local activation of innate immunity and inflammation and an indicator of disease activity while in other studies, correlation between levels of PTX-3 and CRP was found to be weak. ${ }^{14-17}$ In this study, PTX-3, similar to $\mathrm{CRP}$, was found to be associated with $\mathrm{BD}$ but did not show any superiority when compared to CRP. There are limited number of studies investigating PTX-3 levels in rheumatologic diseases. In a study investigating whether PTX-3 is an indicator of small vessel vasculitis activity ${ }^{11}$ in patients with Churg-Strauss syndrome, Wegener's granulomatosis, and microscopic polyangiitis, systemic lupus erythematosus, rheumatoid arthritis, and CREST syndrome (calcinosis, Raynaud's phenomenon, esophageal dysmotility, sclerodactyly, telangiectasia), PTX-3 levels were higher in patients with untreated vasculitis and lower in patients who underwent immunosuppressive treatments $(p<0.005)$. Different from our study, PTX-3 levels did not correlate with CRP levels in patients with vasculitis. ${ }^{11}$

In another study conducted on patients with rheumatoid arthritis, it was shown that PTX-3, unlike CRP, contributed to the complementmediated mechanism causing inflammation and tissue damage. Increased levels of PTX-3 protein was obtained in synovial fluids from patients with rheumatoid arthritis. In contrast to other acute phase reactants, the majority of PTX-3 synthesis is extrahepatic and in that study the main source of PTX-3 was the synovial pannus. ${ }^{12}$
A study in patients with psoriatic arthritis showed a positive correlation between PTX-3 and disease activity of psoriasis. A strong PTX-3 staining in fibroblasts, endothelial cells and monocytes/macrophages was detected in severe psoriatic skin lesions. ${ }^{18}$

Recently, in a Turkish cohort of BD patients similar to our study group, ${ }^{19}$ it was determined that PTX-3 levels did not correlate with CRP or with any domains of BD's current activity form in contrast to our present study. In our study, PTX-3 levels were found to be significantly higher in patients with BD. Since most of the patients of our cohort were in remission, we tried to find out the difference of PTX-3 levels according to BD's site-specific involvement, rather than disease activity. PTX-3 levels did not show any difference according to involvement. We only observed a slight increase in patients who had uveitis. However, this increase was not statistically significant. Our study indicates that PTX-3 can be an alternative parameter to CRP in the followup of BD. However, we need further studies to determine the relationship between PTX-3 and severity of $\mathrm{BD}$.

\section{Declaration of conflicting interests}

The authors declared no conflicts of interest with respect to the authorship and/or publication of this article.

\section{Funding}

The authors received no financial support for the research and/or authorship of this article.

\section{REFERENCES}

1. Verity DH, Wallace GR, Vaughan RW, Stanford MR. Behçet's disease: from Hippocrates to the third millennium. Br J Ophthalmol 2003;87:1175-83. 
2. O'duffy JD. Summary of International Symposium on Behçet's Disease. Istanbul, September 29-30, 1977. J Rheumatol 1978;5:229-33.

3. Yazici H, Fresko I, Yurdakul S. Behçet's syndrome: disease manifestations, management, and advances in treatment. Nat Clin Pract Rheumatol 2007;3:148-55.

4. Zierhut M, Mizuki N, Ohno S, Inoko H, Gül A, Onoé $\mathrm{K}$, et al. Immunology and functional genomics of Behçet's disease. Cell Mol Life Sci 2003;60:1903-22.

5. Tüzün B, Tüzün Y, Yurdakul S, Hamuryudan V, Yazici H, Ozyazgan Y. Neutrophil chemotaxis in Behçet's syndrome. Ann Rheum Dis 1999;58:658.

6. Garlanda C, Bottazzi B, Bastone A, Mantovani A. Pentraxins at the crossroads between innate immunity, inflammation, matrix deposition, and female fertility. Annu Rev Immunol 2005;23:337-66.

7. Norata GD, Marchesi P, Pulakazhi Venu VK, Pasqualini F, Anselmo A, Moalli F, et al. Deficiency of the long pentraxin PTX3 promotes vascular inflammation and atherosclerosis. Circulation 2009; 120:699-708.

8. Doni A, Michela M, Bottazzi B, Peri G, Valentino S, Polentarutti N, et al. Regulation of PTX3, a key component of humoral innate immunity in human dendritic cells: stimulation by IL-10 and inhibition by IFN-gamma. J Leukoc Biol 2006;79:797-802.

9. Reid MS, Blobel CP. Apexin, an acrosomal pentaxin. J Biol Chem 1994;269:32615-20.

10. Noland TD, Friday BB, Maulit MT, Gerton GL. The sperm acrosomal matrix contains a novel member of the pentaxin family of calcium-dependent binding proteins. J Biol Chem 1994;269:32607-14.

11. Fazzini F, Peri G, Doni A, Dell'Antonio G, Dal Cin E, Bozzolo $E$, et al. PTX3 in small-vessel vasculitides: an independent indicator of disease activity produced at sites of inflammation. Arthritis Rheum
2001;44:2841-50

12. Luchetti MM, Piccinini G, Mantovani A, Peri G, Matteucci C, Pomponio G, et al. Expression and production of the long pentraxin PTX3 in rheumatoid arthritis (RA). Clin Exp Immunol 2000;119:196-202.

13. Criteria for diagnosis of Behçet's disease. International Study Group for Behçet's Disease. Lancet 1990;335:1078-80.

14. Peri G, Introna M, Corradi D, Iacuitti G, Signorini S, Avanzini F, et al. PTX3, A prototypical long pentraxin, is an early indicator of acute myocardial infarction in humans. Circulation 2000;102:636-41.

15. Muller B, Peri G, Doni A, Torri V, Landmann R, Bottazzi B, et al. Circulating levels of the long pentraxin PTX3 correlate with severity of infection in critically ill patients. Crit Care Med 2001;29:1404-7.

16. Hess AP, Hamilton AE, Talbi S, Dosiou C, Nyegaard M, Nayak $\mathrm{N}$, et al. Decidual stromal cell response to paracrine signals from the trophoblast: amplification of immune and angiogenic modulators. Biol Reprod 2007;76:102-17.

17. Tong M, Anderstam B, Sjöberg B, Alvestrand A. Circulating levels of long pentraxin 3 (PTX3) are elevated in hemodialysis patients and increase acutely after a single HD session. J Am Soc Nephrol 2006;17:735A. [Abstract]

18. Bevelacqua V, Libra M, Mazzarino MC, Gangemi P, Nicotra G, Curatolo S, et al. Long pentraxin 3: a marker of inflammation in untreated psoriatic patients. Int J Mol Med 2006;18:415-23.

19. Yazmalar L, Batmaz İ, Sula B, Alpaycı M, Aydın F, Türkçü F, et al. Serum levels of alpha-1 acid glycoprotein and pentraxin 3 in patients with Behçet's disease and relationship with disease activity. Int $J$ Dermatol 2015;54:394-400. 